\title{
Effect of Pre-heat Treatment on Hardening Behavior in Gas Nitrocarburized Carbon Steel
}

\author{
Masato YUYA, ${ }^{1{ }^{*}}$ Naoyuki SANO, ${ }^{2)}$ Hiroaki TAHIRA, ${ }^{3)}$ Makoto EGASHIRA ${ }^{4)}$ and Shigefumi NISHITANI ${ }^{5)}$ \\ 1) Steel Research Laboratories, Nippon Steel \& Sumitomo Metal Corporation, 20-1 Shintomi, Futtsu, Chiba, $293-8511$ Japan. \\ 2) Advanced Technology Research Laboratories, Nippon Steel \& Sumitomo Metal Corporation, 20-1 Shintomi, Futtsu, Chiba, \\ 293-8511 Japan. $\quad 3$ 3) Osaka Steel Works, Nippon Steel \& Sumitomo Metal Corporation, 1-109, Shimaya 5-chome, \\ Konohana-ku, Osaka, 554-0024 Japan. $\quad 4)$ Yawata R\&D Laboratories, Nippon Steel \& Sumitomo Metal Corporation, 1-1, \\ Tobihata, Tobata, Kitakyushu, Fukuoka, 804-8501 Japan. $\quad$ 5) Yawata Works, Nippon Steel \& Sumitomo Metal Corpora- \\ tion, 1 Konomi-machi, Kokurakita-ku, Kitakyushu, Fukuoka, 802-8686 Japan.
}

(Received on January 18, 2016; accepted on March 22, 2016)

\begin{abstract}
To investigate the effect of the pre-heat treatments on hardening behavior in plane carbon steel during gas nitrocarburizing process, Fe-0.4mass\%C-0.2mass\%Si-0.8mass\%Mn steel was nitrocarburized after pre-heat treatments, normalizing and low-temperature annealing. Hardness and nitrogen concentration in nitrocarburized layer of the normalized and annealed steel was lower than that of steel without pre-heat treatment. Nitrocarburized microstructure was observed by transmission electron microscopy. The observation showed that iron nitrides $\alpha^{\prime \prime}-\mathrm{Fe}_{16} \mathrm{~N}_{2}$ were precipitated. The $\alpha^{\prime \prime}-\mathrm{Fe}_{16} \mathrm{~N}_{2}$ grains formed in the normalized and annealed steel was larger than that in the steel without pre-heat treatment. These results suggest that both the nitrogen concentration and precipitation behavior of $\alpha^{\prime \prime}-\mathrm{Fe}_{16} \mathrm{~N}_{2}$ in the nitrocarburizing process contribute to the difference of the amount of hardening between the pre-heat treated steel and steel without pre-heat treatment.
\end{abstract}

KEY WORDS: nitriding; nitrocarburizing; $\mathrm{Fe}_{16} \mathrm{~N}_{2}$; solid solution hardening; precipitation hardening.

\section{Introduction}

Nitriding and nitrocarburizing are surface hardening heat treatments that are widely used to improve fatigue and/or wear properties of steel parts. On nitrocarburized steels containing a sufficient amount of alloying elements, such as $\mathrm{Cr}$ and $\mathrm{Al}$, with high affinity for $\mathrm{N}$, a lot of alloy nitrides are precipitated, and those nitrides contribute to hardening. ${ }^{1-3)}$ Low alloy steels which contain only a small quantity of nitride-forming elements also can be hardened by nitrocarburizing. ${ }^{4-7)}$ Quenching from nitrocarburizing temperature makes nitrogen into supersaturated solution. In typical industrial nitrocarburizing with oil quenching process, a portion of entering nitrogen may be precipitated as iron nitrides of $\gamma^{\prime}-\mathrm{Fe}_{4} \mathrm{~N}$ or $\alpha{ }^{\prime \prime}-\mathrm{Fe}_{16} \mathrm{~N}_{2}$ in the cooling process. ${ }^{8,9)}$ As mentioned above, nitrogen can be existed as various states in nitrocarburized carbon steels.

Various pre-heat treatments, such as normalizing, lowtemperature annealing, and quenching and tempering, are performed to optimize microstructure in carbon steels. It is empirically known that the amount of hardening by nitrocarburizing is affected by the pre-heat treatments carried out before nitrocarburizing. ${ }^{10,11)}$ Although this effect of the pre-heat treatments seems to be caused by the various state of nitrogen in the microstructure, the microscopic behavior

\footnotetext{
* Corresponding author: E-mail: yuya.53z.masato@jp.nssmc.com
} DOI: http://dx.doi.org/10.2355/isijinternational.ISIJINT-2016-034 of nitrogen is not sufficiently understood.

The purpose of this work is to investigate the various state of nitrogen in the nitrocarburized carbon steels, and to clarify the effect of the pre-heat treatments on the hardening behavior.

\section{Experimental}

An iron-based alloy of composition $\mathrm{Fe}-0.41$ mass $\%$ $\mathrm{C}-0.2 \mathrm{mass} \% \mathrm{Si}-0.8 \mathrm{mass} \% \mathrm{Mn}$ was vacuum melted and casted into a ingot. The ingot was heated at $1523 \mathrm{~K}$, and forged into round bars of $50 \mathrm{~mm}$ in diameter. Some of these bars were normalized at $1123 \mathrm{~K}$ for $3.6 \mathrm{ks}$ or annealed at $923 \mathrm{~K}$ for $21.6 \mathrm{ks}$. Square bar specimens of $10 \times 10 \times 80 \mathrm{~mm}$ and cylindrical specimens of $40 \mathrm{~mm}$ in diameter and $50 \mathrm{~mm}$ in length were cut from the forged bars that were given preheat treatment or non-pretreated. These specimens were nitrocarburized with a gas mixture of $50 \% \mathrm{NH}_{3}: 50 \% \mathrm{RX}$ gas at $853 \mathrm{~K}$ for $7.2 \mathrm{ks}$. At the end of the nitrocarburizing process, the specimens were quenched into an oil bath kept at $373 \mathrm{~K}$. Hardness profile was measured by a Vickers hardness tester on a cross-sectional surface of the nitrocarburized layer. X-ray diffraction analysis was performed with Co K $\alpha$ radiation $(\lambda=0.1789 \mathrm{~nm})$ on the core region of nitrocarburized specimens, and full width at half maximum (FWHM) of the $\{211\}$ ferrite peak was analyzed.

Nitrogen concentration of the nitrocarburized layer was determined in the depth direction by every $50 \mu \mathrm{m}$ step. 
The cylindrical specimens were peeled every $50 \mu \mathrm{m}$ thick, and nitrogen concentration in collected chips was measured by thermal conductivity detector. Thin foil specimens for transmission electron microscope (TEM) observation were prepared from the depth of $75 \mu \mathrm{m}$ in the nitrocarburized bar's surfaces.

Nitrogen in the nitrocarburized steels seems to exist as dissolved nitrogen or a part of precipitates, such as $\gamma^{\prime}$ and $\alpha$ ". In order to control the nitrogen state, following post-heat treatments were performed on the bar specimen after nitrocarburizing. First, sheet specimens of $3 \mathrm{~mm}$ thick having nitrocarburized surface were cut from the nitrocarburized bars. These sheets were heated at $853 \mathrm{~K}$, the same temperature as nitrocarburizing, for $900 \mathrm{~s}$ and quenched into water so that the nitrogen can fully dissolve into the matrix. The dissolved nitrogen can be precipitated mainly as $\alpha$ " at temperature below $573 \mathrm{~K}$, and as $\gamma^{\prime}$ at temperature above $573 \mathrm{~K}^{12,13)}$ Therefore, aging at appropriate temperature can make nitrogen precipitate as required iron nitrides, $\alpha$ " and $\gamma^{\prime}$.

In order to precipitate $\alpha$ ", the quenched sheets were heated at $423 \mathrm{~K}$ for $21.6 \mathrm{ks}$ and cooled to room temperature in a furnace. Most of nitrogen were precipitated as $\alpha$ " in these specimens.

Aging to precipitate $\gamma^{\prime}$ is performed as follows. First, a part of quenched sheets were heated and kept at $623 \mathrm{~K}$ for $7.2 \mathrm{ks}$. Then, they were cooled to $573 \mathrm{~K}$ at a rate of $0.8 \mathrm{~K} / \mathrm{min}$ and kept for $3.6 \mathrm{ks}$. Subsequently, they were cooled similarly by $50 \mathrm{~K}$ step and kept at that temperature for $3.6 \mathrm{ks}$, until reaching $423 \mathrm{~K}$. Finally, sheets were cooled to room temperature in a furnace.Hardness profiles of the nitrocarburized layer of those specimens were also measured.

\section{Results}

\subsection{Microstructures}

Optical micrographs of the cross sections of the nitrocarburized specimens are shown in Fig. 1. In all specimens, the microstructure consists of ferrite and pearlite. Table 1 shows FWHM of the $\{211\}$ ferrite peak in the specimens. The FWHM of the non-pretreated specimen is larger than those of the pre-treated specimens. Because ferrite grain size is several micrometers or more, effect of grain size on the FWHM is negligible. Therefore, the difference of FWHM is mainly caused by change in the amount of lattice defect, such as dislocation.

\subsection{Hardness Profiles}

Figure 2 shows the effect of the pre-heat treatments, normalizing and low-temperature annealing before nitrocarburizing, on the hardness profiles. The hardness of the nitrocaburized layer of the pre-treated specimens is lower than that of the non-pretreated specimen. The hardness of the core region also decreases by these pre-heat treatment. Increment in hardness of the nitrocarburized layer relative to the core part is defined as a degree of hardening, $\Delta \mathrm{HV}$. Figure 3 shows $\Delta H V$ profiles as a function of the depth from the surface of these specimens. Clearly, $\Delta \mathrm{HV}$ of the pre-treated specimen is less than that of the non-pretreated specimen.
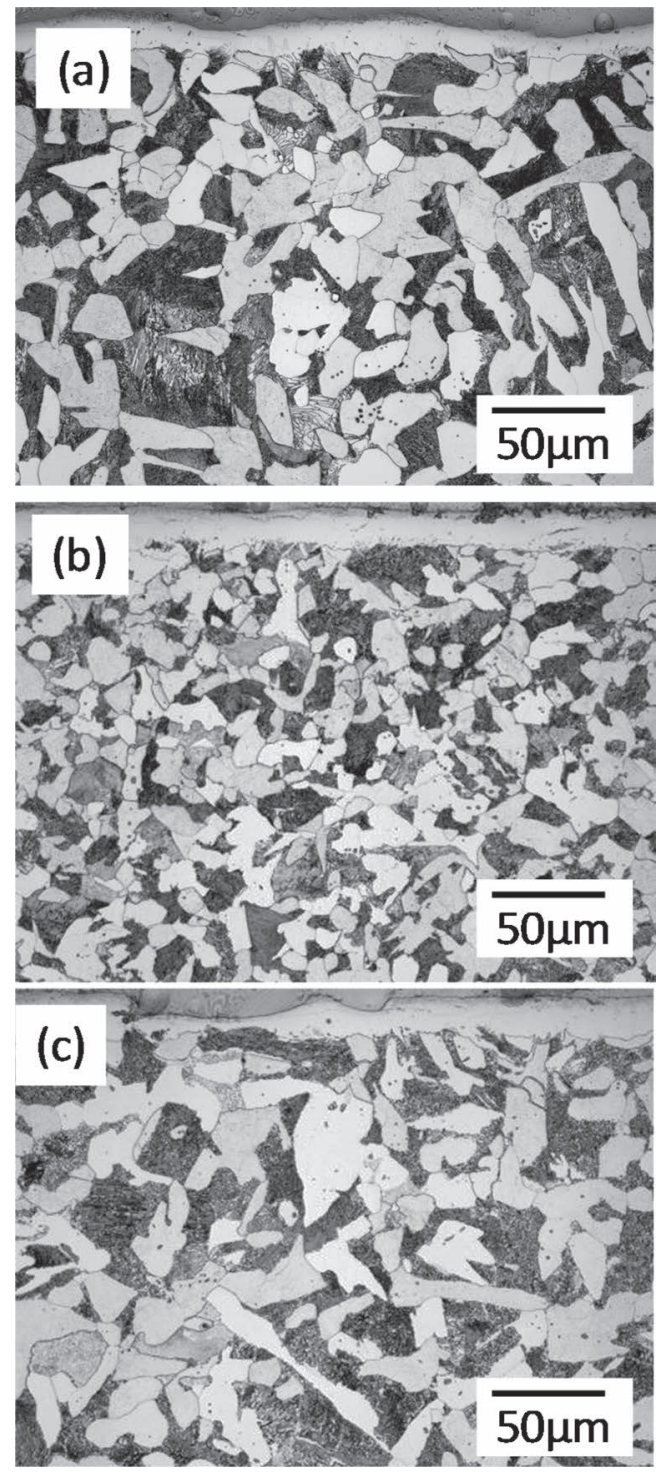

Fig. 1. Optical micrographs of the cross sections of the nitrocarburized surface in (a) non-pretreated Specimen, (b) normalized specimen, and (c) low-temperature annealed specimen.

Table 1. Full width at half maximum of the $\{211\}$ ferrite peak measured by XRD with Co K $\alpha$ radiation.

\begin{tabular}{ccc}
\hline non-Pretreated & normalized & $\begin{array}{c}\text { low-temperature- } \\
\text { annealed }\end{array}$ \\
\hline $0.200^{\circ}$ & $0.180^{\circ}$ & $0.167^{\circ}$ \\
\hline
\end{tabular}

\subsection{Nitrogen Concentration Profiles}

Effect of the pre-heat treatment on the nitrogen concentration profiles is shown in Fig. 4. From the surface to a depth of around $200 \mu \mathrm{m}$, the nitrogen concentration of the pre-treated specimen is lower than that of the non-pretreated specimen. At a depth of $50 \mu \mathrm{m}$ from the surface, the nitrogen concentration in the pre-treated specimens decreases by around $10 \%$, as compared to in the non-pretreated specimen. The effect of the pre-heat treatment on the nitrogen concentration near the surface is quite similar to that on hardness. This implies that one of the reasons for the lower $\Delta \mathrm{HV}$ in the pre-treated specimen is the lower nitrogen concentration. 


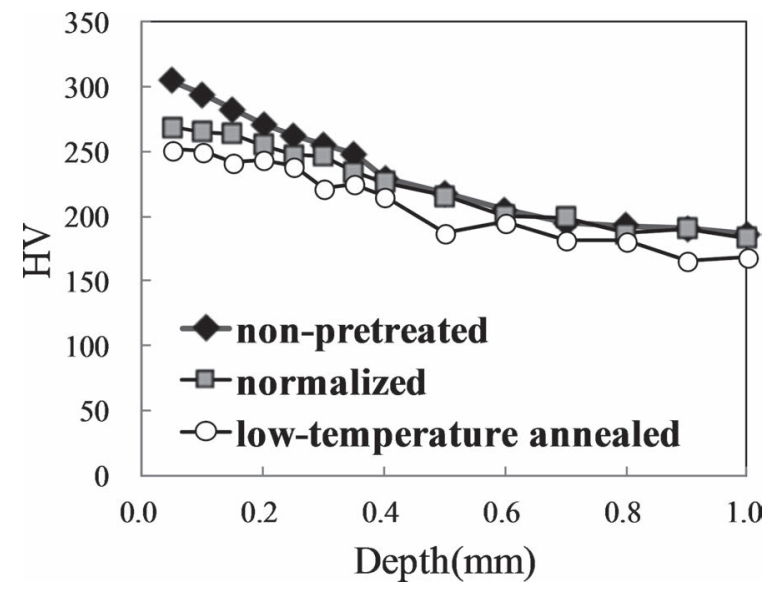

Fig. 2. Effect of the pre-heat treatments before nitrocarburizing on hardness profiles of the nitrocarburized layer.

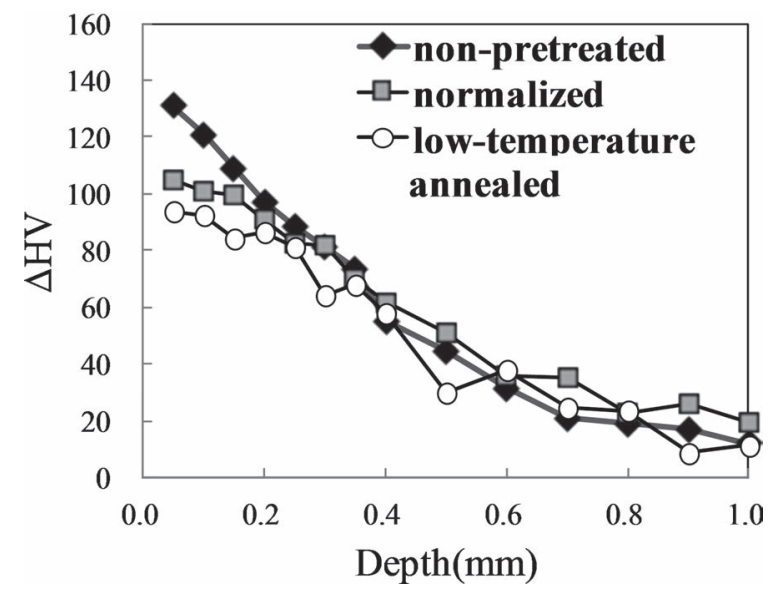

Fig. 3. Effect of the pre-heat treatments on amount of hardening of the nitrocarburized layer.

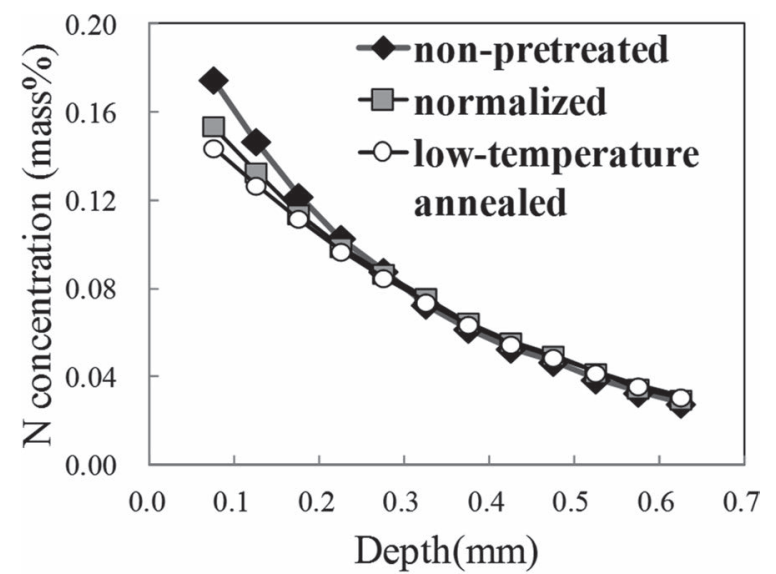

Fig. 4. Effect of the pre-heat treatments on nitrogen concentration profiles of the nitrocarburized layer.

The nitrogen concentration profiles at deeper depths in Fig. 4 are magnified in Fig. 5. In contrast to the surface region, the nitrogen concentration in the pre-treated specimen is slightly larger than that of the non-pretreated specimen. This result suggests that diffusion of dissolved nitrogen from surface to core is suppressed in non-pretreated specimen. Normalizing or low-temperature-annealing reduces dislocations that can attract and trap dissolved nitrogen. ${ }^{14)}$

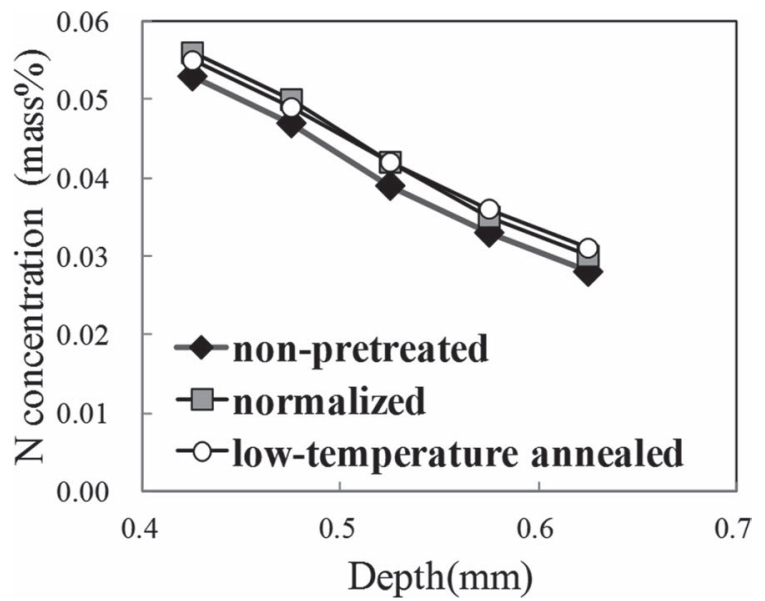

Fig. 5. Effect of the pre-heat treatments on nitrogen concentration profiles of a deeper region in the nitrocarburized layer.

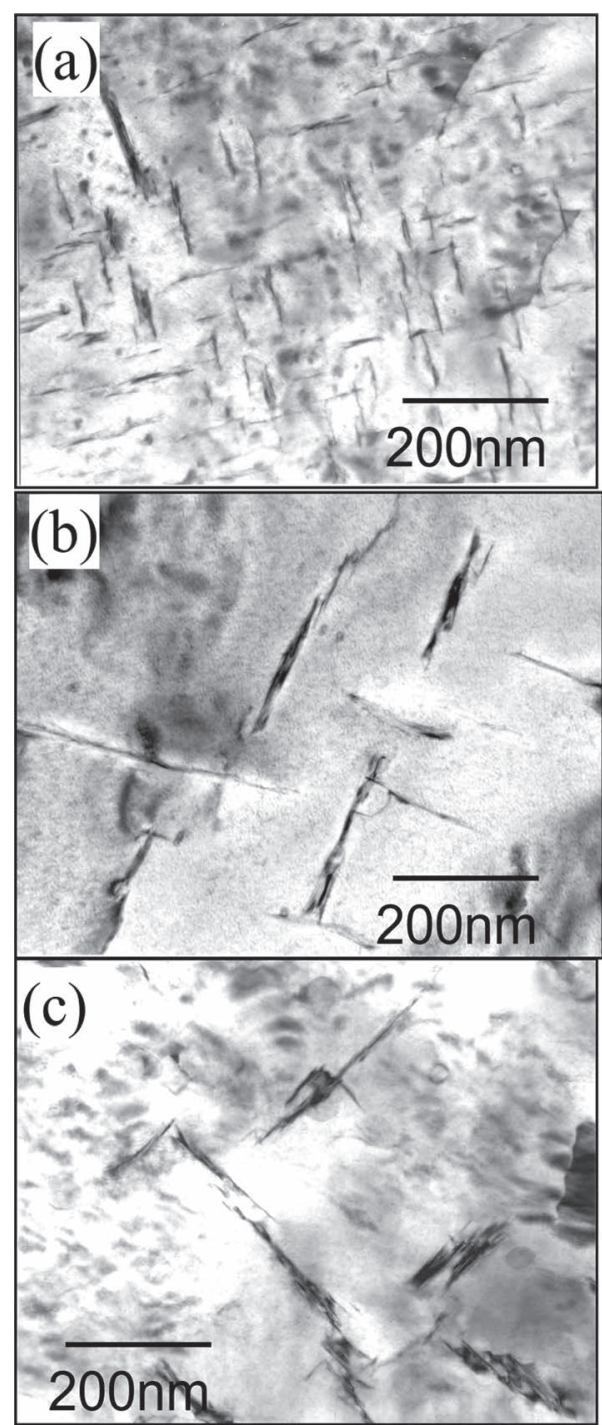

Fig. 6. The TEM bright field images taken at a depth of $75 \mu \mathrm{m}$ below the surface in (a) non-pretreated specimen, (b) normalized specimen, and (c) low-temperature annealed specimen.

Therefore, higher dislocation density can increase the solid solubility limit of nitrogen and disturb nitrogen diffusion to the core region. 


\subsection{TEM Observation}

TEM bright field images taken at a depth of $75 \mu \mathrm{m}$ below the surface are shown in Fig. 6. Plate-like precipitates are observed in all specimens. The selected area diffraction pattern taken in the non-pretreated specimen is shown in Fig. 7(a) (Zone axis: [100] $\alpha$ ). At first glance, the pattern exhibits no diffraction spots distinctly different from that of matrix. However, some spots indicated by arrows in Fig. 7(a) can be clearly separated from the spots originated from the matrix. These separated spots indicate the existence of other phase whose crystal structure is slightly different from that of the matrix. Crystal lattice of iron nitrides $\varepsilon-\mathrm{Fe}_{2-3} \mathrm{~N}$ and $\gamma^{\prime}-\mathrm{Fe}_{4} \mathrm{~N}$ do not have lattice plane whose lattice parameter is close to that of the matrix $\{110\}$ and $\{200\} .{ }^{15)}$ Therefore, these separated spots seems to be attributed to $\alpha$ " whose crystal structure is similar to the matrix. ${ }^{16,17)}$

The size of the precipitates in the non-pretreated specimen is about $100 \mathrm{~nm}$ long and several nanometers thick. The precipitates in the pre-treated specimens are larger than those in the non-pretreated specimen. Some of the precipitates are magnified in Fig. 8(a), and a dark field image in the same area with Fig. 8(a) is displayed in Fig. 8(b). The enlarged photo shows the large $\alpha$ " precipitate is an aggregate of multiple fine $\alpha$ " plates. The single plate in the aggregate is around $100 \mathrm{~nm}$ long and is little different from the plate in the non-pretreated specimen. The contribution of these $\alpha$ " to hardness is discussed in a later section.
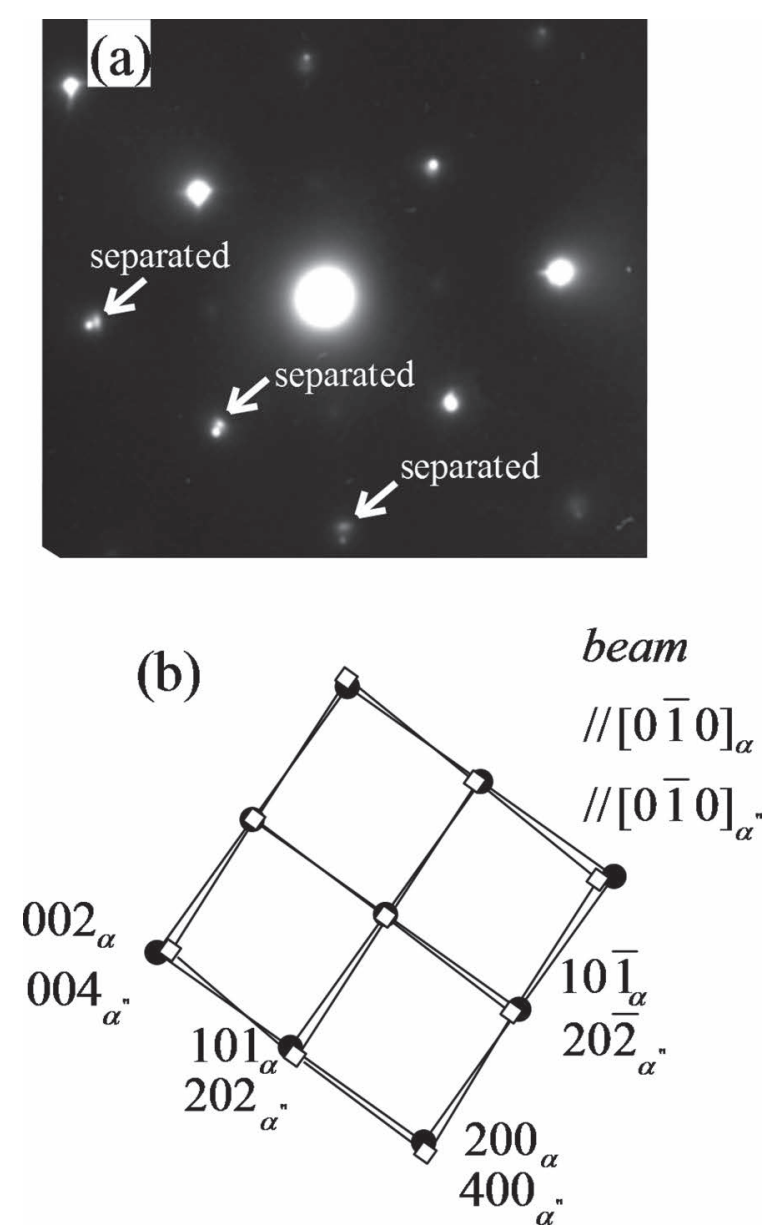

Fig. 7. (a) Selected area diffraction pattern taken in the nitrocarburized layer of the non-pretreated specimen: (b) corresponding key diagram to (a).

\subsection{Post Heat Treatments after Nitrocarburizing}

Figure 9 shows scanning electron microscope images of nitrocarburized layer at a depth of $100 \mu \mathrm{m}$ from the surface in the post-heat-treated specimen. In the specimen re-heated and quenched after nitrocarburizing, no iron nitrides can be observed (Fig. 9(a)). Therefore, most nitrogen in this solution treated specimen seems to exist as dissolved nitrogen. Whereas, in the specimen aged $623 \mathrm{~K}$ after solution treatment, coarse rod-shaped precipitates are observed (Fig. 9(b)). Because $\alpha$ " is not stable at higher temperature, these precipitates are $\gamma^{\prime}$.

In the specimen aged at $423 \mathrm{~K}$ after solution treatment, many fine precipitates are observed (Fig. 9(c)). These fine precipitates are clearly different from precipitates in the specimen aged $623 \mathrm{~K}$ in size. Thus, these precipitates are seemed to be $\alpha$ ".

Effect of the post-heat treatments after nitrocarburizing on hardness profiles in the non-pretreated specimen is shown in Fig. 10. The hardness at nitrocarburized layer in the specimen aged at $423 \mathrm{~K}$ is reduced as compared to that in the solution treated specimen. In addition, the hardness is decreased more drastically by aging at $623 \mathrm{~K}$. Since substitutional alloying elements are not able to diffuse at temperature of $423 \mathrm{~K}$ and $623 \mathrm{~K}$, precipitation of alloy nitrides in these aging conditions is negligible. Thus, lower hardness in the aged specimen seems to be caused by the reaction that the dissolved nitrogen precipitates as iron nitrides. Effect of the post-heat treatment on hardness profiles in normalized specimens and in low-temperature annealed specimen are shown in Figs. 11 and 12, respectively. The aging treatment reduces the surface hardness in these specimens like the case of the non-pretreated specimen. The amount of decrease in hardness by aging treatment at $473 \mathrm{~K}$ in the pre-treated specimens is larger than that in the non-pretreated specimen.

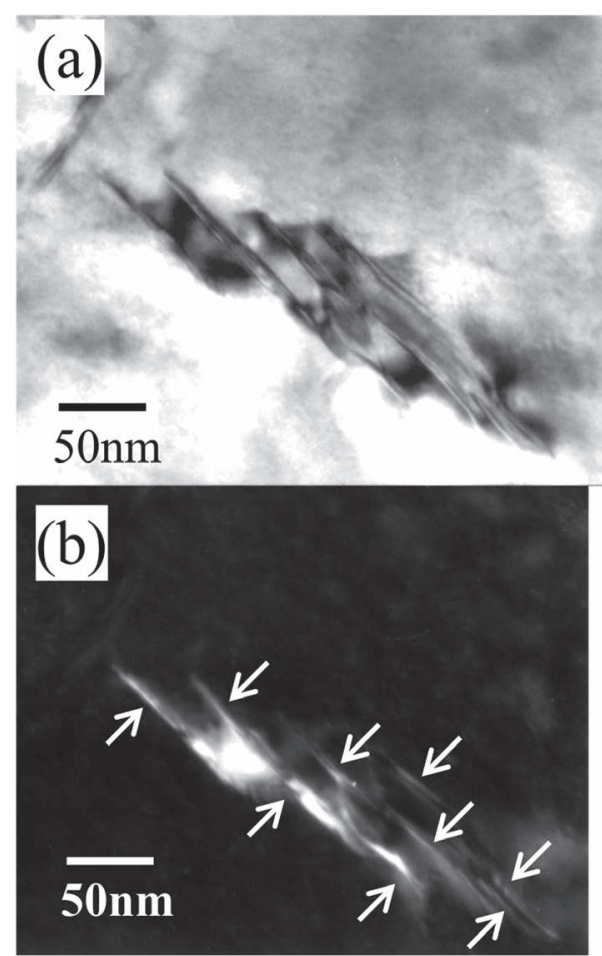

Fig. 8. Enlarged view of clustering $\alpha$ ' $-\mathrm{Fe}_{16} \mathrm{~N}_{2}$ in the specimen nitrocarburized after low-temperature annealing: (a) bright field image; (b) dark field image. 

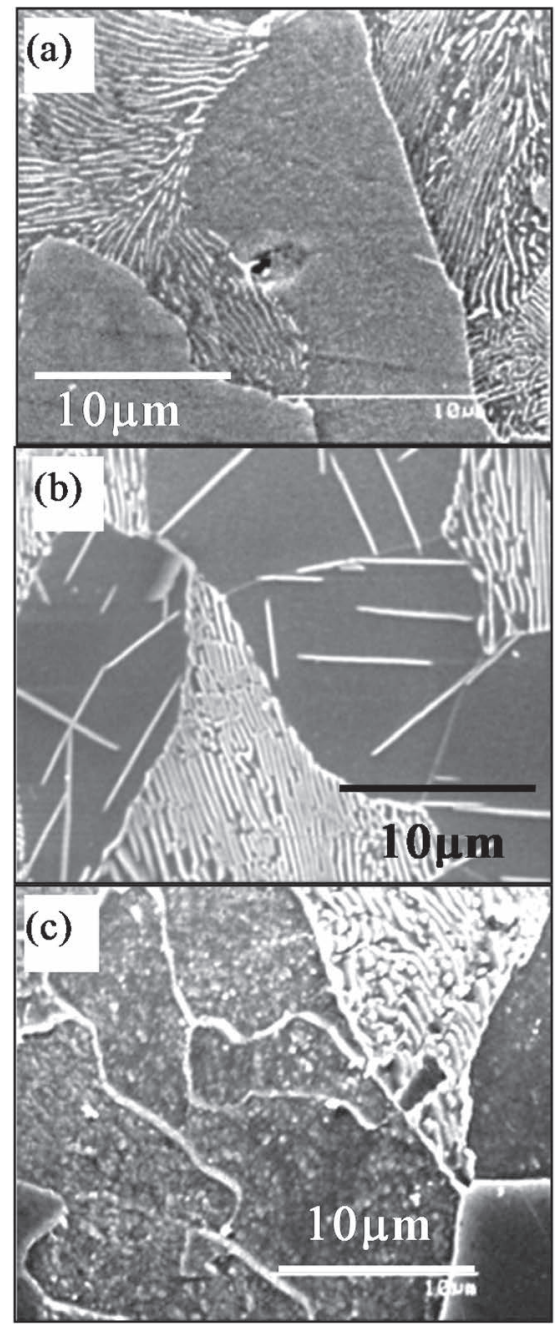

Fig. 9. Scanning electron microscope images taken at a depth of $100 \mu \mathrm{m}$ below the surface in the specimen post-heattreated under various conditions. (a) solution treated specimen, (b) aged at $623 \mathrm{~K}$ after solution treatment, (c) aged at $423 \mathrm{~K}$ after solution treatment.

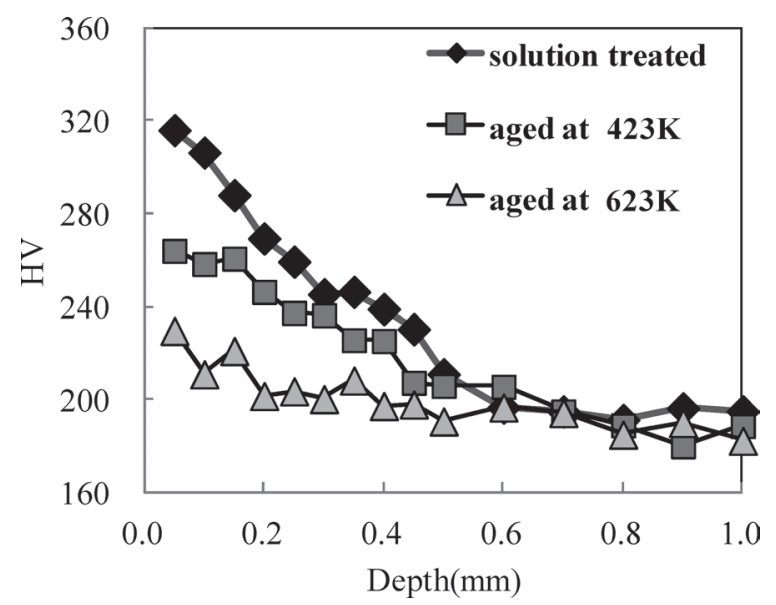

Fig. 10. Effect of various post-heat treatments on hardness profiles of the nitrocarburized layer of the non-pretreated specimen.

\section{Discussion}

\subsection{Effect of Nitrogen Concentration on Hardness}

As mentioned above, if steels are normalized or lowtemperature annealed before nitrocarburizing, increment

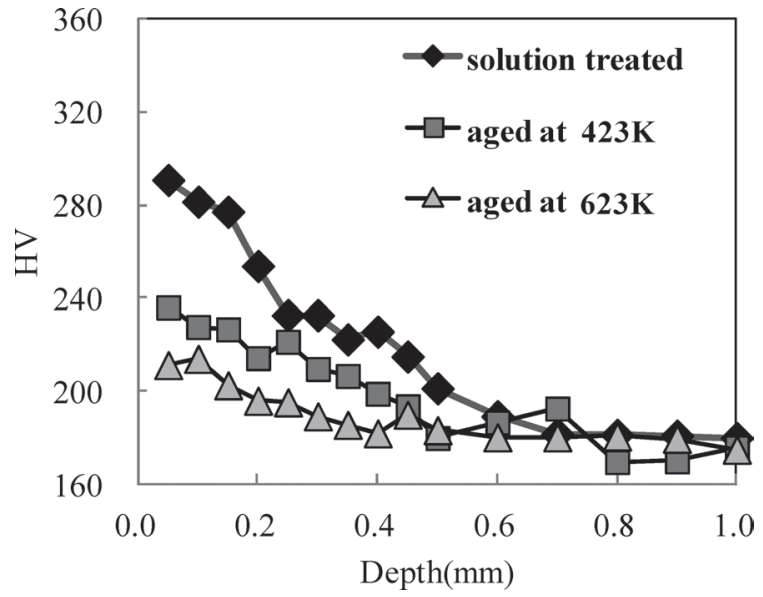

Fig. 11. Effect of various post-heat treatments on hardness profiles of the nitrocarburized layer of the specimen normalized before nitrocarburizing.

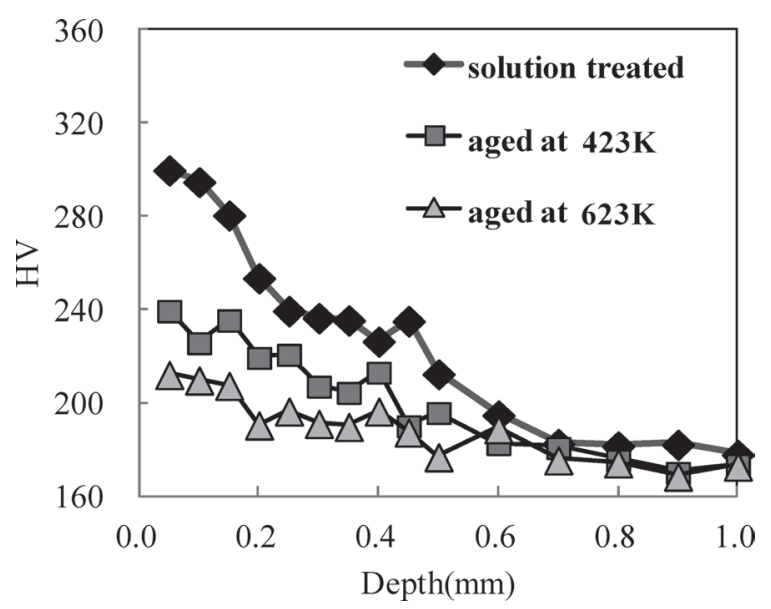

Fig. 12. Effect of various post-heat treatments on hardness profiles of the nitrocarburized layer of the specimen annealed before nitrocarburizing.

of hardness and nitrogen concentration at nitrocarburized layer are lower than that in non-pretreated specimen. In this section, we discuss the relation between the nitrogen concentration and the hardness increment. It is well known that Fleischer-Friedel theory explains an effect of alloying elements on solid solution strengthening. ${ }^{18)}$ In this theory, increment in critical shear stress of material is proportional to increment in square root of concentration of substitutional alloying element. Here, we assume hardening ability of dissolved nitrogen is in accordance with their theory, and examine the increment in hardness with nitrogen concentration.

Figure 13 describes the effect of the pre-heat treatment on the relation between the hardness increment and the square root of nitrogen concentration. Here, the hardness in Fig. 13 was interpolated from experimental data, because the data pitch in the hardness measurement differed from that in the nitrogen concentration measurement. In the region with lower concentration of nitrogen, $\Delta \mathrm{HV}$ increases linearly with the square root of nitrogen concentration. However, in the region with higher concentration of nitrogen, the higher the nitrogen concentration become, the smaller the ratio of $\Delta \mathrm{HV}$ to the square root of nitrogen concentration become. This result indicates that the increment of hardness is mainly 


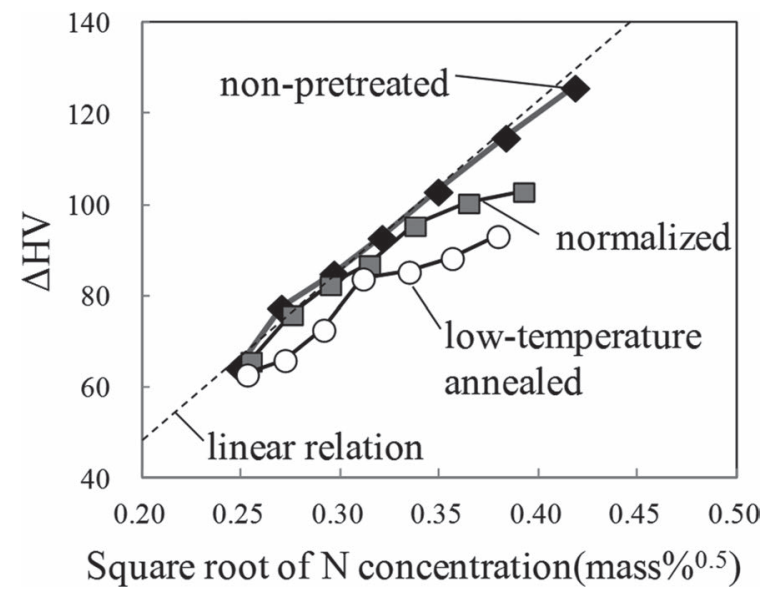

Fig. 13. Effect of the pre-heat treatments on relation between $\Delta \mathrm{HV}$ and square root of nitrogen concentration in the nitrocarburized layer.

influenced by the dissolved nitrogen in the near core region including less amount of nitrogen. In addition, in the near surface region including a good amount of nitrogen, the nitrides precipitation affects the hardness there.

\subsection{Effect of $\alpha$ "- $\mathrm{Fe}_{16} \mathrm{~N}_{2}$ on Hardness}

The presence of nitrogen is categorized into three states, namely, dissolved nitrogen, iron nitrides, such as $\gamma^{\prime}$ and $\alpha$ ", and alloy nitrides. We discuss a relation between the nitrogen state and the hardness increment on the basis of the hardness data of specimens post-heat treated after nitrocarburizing.

Water quenching can suppress precipitation of iron nitrides during cooling from nitrocarburizing temperature. In the nitrocarburized layer in quenched specimen, most of nitrogen is dissolved. This nitrogen can be precipitated as iron nitrides of $\alpha$ ' and $\gamma^{\prime}$ when aged at $423 \mathrm{~K}$ and $623 \mathrm{~K}$, respectively. It seems reasonable to assume that $\gamma^{\prime}$ precipitates are too coarse (Fig. 9(b)) to harden the matrix. Therefore, the amount of solid solution hardening by dissolved nitrogen, $\Delta \mathrm{HV}_{\mathrm{SH}}$, is assumed to be described as a difference between the amount of hardening in quenched specimen and that in specimen aged at $623 \mathrm{~K}$ (Eq. (1)).

$$
\Delta H V_{S H}=\Delta H V_{\text {sol }}-\Delta H V_{350}
$$

where $\Delta \mathrm{HV}_{\mathrm{sol}}$ is the amount of hardening of the quenched specimen, and $\mathrm{HV}_{350}$ is that of the specimen aged at $623 \mathrm{~K}$.

The $\alpha$ " has body-centered tetragonal structure. An interatomic distance of $[100]_{\alpha}$, direction is close to that of $[100]_{\text {matrix }}$, the difference within $0.3 \% .^{19,20)}$ This difference is small enough that $\alpha$ " precipitates on the matrix (001) plane coherently or semi-coherently. Therefore, the fine $\alpha$ " precipitates observed in the TEM photos can harden the matrix by precipitation hardening. ${ }^{21)} \mathrm{We}$ assume that the most of nitrogen is precipitated as $\alpha$ " in specimen aged at $423 \mathrm{~K}^{22)}$ Under this assumption, the amount of precipitation hardening with the $\alpha ", \Delta \mathrm{HV}_{\mathrm{PH}}$, can be described as the difference between the amount of hardening in the quenched specimen and that in the specimen aged at $423 \mathrm{~K}$ (Eq. (2)).

$$
\Delta H V_{P H}=\Delta H V_{150}-\Delta H V_{350}
$$

where $\Delta \mathrm{HV}_{150}$ is the hardness at an arbitrary depth in the

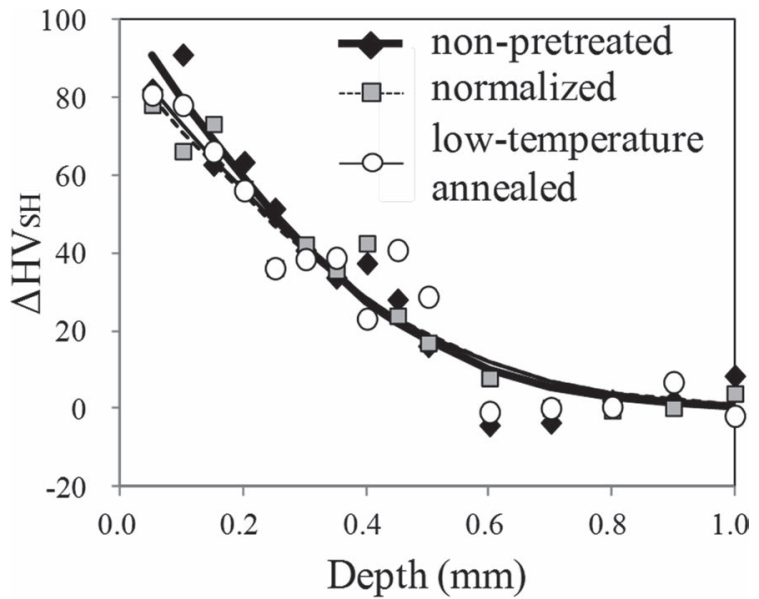

Fig. 14. Effect of the pre-heat treatments on hardening ability by solid solution hardening with dissolved nitrogen.

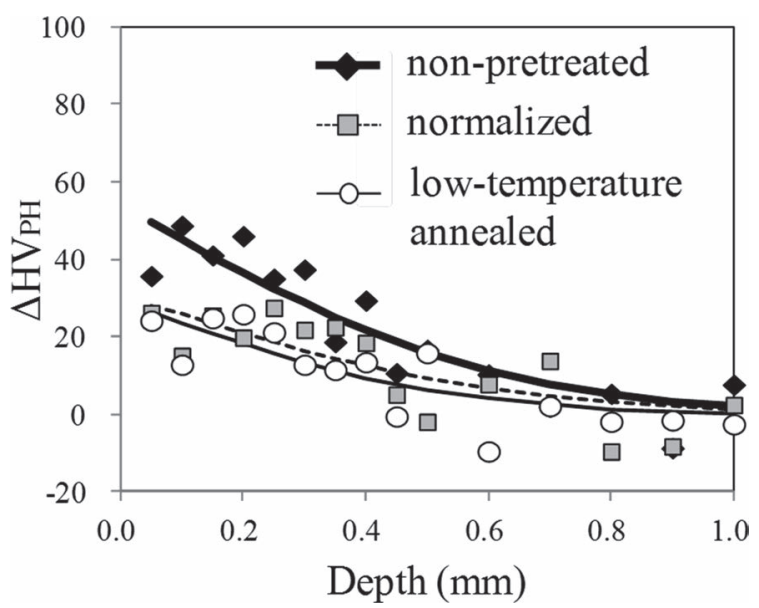

Fig. 15. Effect of the pre-heat treatments on hardening ability by precipitation hardening with $\alpha$ '- $\mathrm{Fe}_{16} \mathrm{~N}_{2}$.

specimen aged at $423 \mathrm{~K}$. Figures 14 and 15 represent $\Delta \mathrm{HV}_{\mathrm{SH}}$ and $\Delta \mathrm{HV}_{\mathrm{PH}}$ profiles derived from Eqs. (1) and (2), respectively. $\Delta \mathrm{HV}_{\mathrm{SH}}$ is not affected by the pre-treatment before nitrocarburizing. On the other hand, $\Delta \mathrm{HV}_{\mathrm{PH}}$ in the pre-treated specimens is smaller than that in the nonpretreated specimen.

As mentioned previously, the pre-treatment before nitrocarburizing changed the nitrogen concentration at nitrocarburized layer. In order to eliminate the effect of difference in the concentration, the depth position containing $0.12 \%$ nitrogen was defined as a standard position in each specimen. The data sets of $\Delta \mathrm{HV}_{\mathrm{SH}}$ and $\Delta \mathrm{HV}_{\mathrm{PH}}$ in Figs. 14 and 15 are smoothed by curve fitting with error function in order to minimize an effect of measurement error. The value of $\Delta \mathrm{HV}_{\mathrm{PH}}$ and $\Delta \mathrm{HV}_{\mathrm{SH}}$ at the standard position in each specimen are obtained with this procedure, and the results are summarized in Fig. 16. The hardening ability by solid solution hardening at the standard position is not affected by the pre-heat treatment. On the otherhand, the hardening ability by the precipitation hardening in the nonpretreated specimen is larger than that in the pre-treated specimens. This result implies that the hardening ability of precipitation hardening with $\alpha$ " is reduced by normalizing and low-temperature annealing. TEM observation shows a relatively large number of fine $\alpha$ " plates are precipitated 


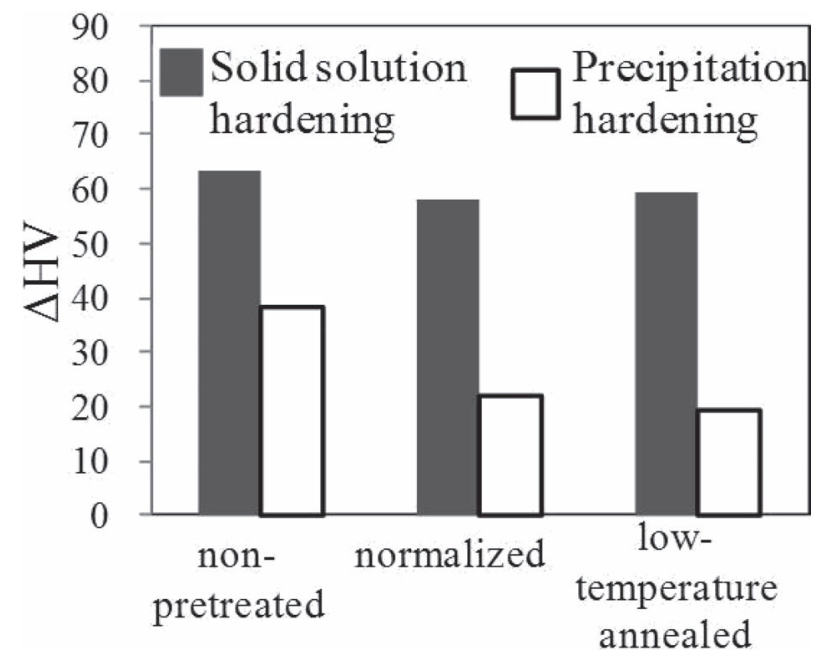

Fig. 16. Hardening ability by solid solution hardening and precipitation hardening at the depth where nitrogen concentration is 0.12 mass $\%$ in.

in the non-pretreated specimen, while $\alpha$ " in the pre-treated specimens forms large aggregates (Fig. 6). This coarsening of $\alpha$ " precipitates seems to result in the decrement of precipitation hardening ability.

\subsection{Mechanism of Forming Clusters of $\alpha$ "}

On the basis of X-ray diffraction analysis, dislocation density in the pre-treated specimens is considered to be lower than that in non-pretreated specimen.In the nonpretreated specimen, $\alpha$ " can be precipitated as many fine plates because of high density of nucleation sites. A relatively low density of the sites may lead to large aggregates formation as described below. Right after the quenching from nitrocarburizing temperature, $\alpha$ " plates precipitate on dislocations already introduced before nitrocarburizing. As the precipitates increase, available nucleation sites on dislocations decrease. Eventually, it become harder for $\alpha$ " to nucleate on dislocations. Later, $\alpha$ " plates precipitate on strain fields induced by the $\alpha$ " precipitated at the early stage and, in consequence, form large clustering aggregates.

\section{Summary}

The influence of a pre heat-treatment before nitrocarburizing on the hardening behavior during nitrocarburizing was investigated using a medium carbon steel JIS S40C. The following conclusions were obtained from measurement of hardness and nitrogen concentration profiles and TEM observation.

(1) Normalizing and low temperature annealing reduces the amount of hardening and the nitrogen concentration near the surface compared to non-pretreated specimen.

(2) Iron nitrides of $\alpha$ " finely precipitate in the nonpretreated specimen. On the other hand, $\alpha$ " precipitate as large clustering aggregates in the pre-heat treated specimen.

(3) The smaller amount of hardening in the pre-treated specimen is seemed to be caused by the coarsening of $\alpha$ " and the decreased hardening ability of $\alpha$ ".

\section{REFERENCES}

1) G. Miyamoto, Y. Tomio, H. Aota, K. Oishi, K. Hano and T. Furuhara: Mater. Sci. Technol., 27 (2011), 742

2) D. H. Jack: Acta Metall., 24 (1976), 137.

3) J. H. Driver and J. M. Papazian: Acta Metall., 21 (1973), 1139.

4) T. Takase: Tetsu-to-Hagané, 66 (1980), 1423.

5) A. Wells and M. P. Shaw: Wear, 103 (1985), 29

6) N. Krishnaraj, K. J. L. Iyer and S. Sundaresan: Wear, 210 (1997), 237.

7) Y. H. Qiang, S. R. Ge and Q. J. Xue: Wear, 218 (1998), 232.

8) E. J. Mittemeijer, A. B. P. Vogels and P. J. Van Der Schaaf: J. Mater. Sci., 15 (1980), 3129.

9) V. Raghavan: Phase Diagrams of Ternary Iron Alloys, ASM International, Geauga, OH, (1989), 143.

10) M. Egashira, M. Yuya and N. Sano: CAMP-ISIJ, 20 (2007), 479

11) M. Yuya: CAMP-ISIJ, 25 (2012), 300, CD-ROM.

12) M. Sakamoto and Y. Imai: J. Jpn. Inst. Met., 44 (1980), 1329.

13) K. Abiko and Y. Imai: Trans. Jpn. Inst. Met., 18 (1977), 113.

14) K. Kamber, D. Keefer and C. Wert: Acta Metall., 9 (1961), 403.

15) H. Jacobs, D. Rechenbach and U. Zachwieja: J. Alloy. Compd., 10 (1995), 227.

16) H. Tanaka, S. Nagakura, Y. Nakamura and Y. Hirotsu: Acta Mater., 45 (1997), 1401.

17) D. H. Jack and K. H. Jack: Mater. Sci. Eng., 11 (1973), 1.

18) J. Friedel: Dislocation, Addison-Wesley, Boston, (1964), 378.

19) U. Dahmen, P. Ferguson and K. H. Westmacott: Acta Metall., 35 (1987), 1037.

20) G. Hinojosa, J. Oseguera and P. S. Schabes-Retchkiman: Thin Solid Films, 349 (1999), 171.

21) X. C. Xiong, A. Redjaïmia and M. Gouné: Scr. Mater., 63 (2010), 1232.

22) C. Wert: Acta Metall., 2 (1954), 361 